Article

\title{
Cost/Performance Analysis of Commercial-Grade Organic Phase-Change Materials for Low-Temperature Heat Storage
}

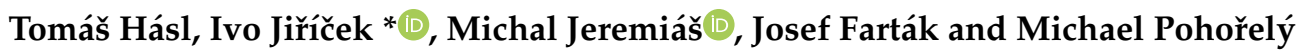 \\ Department of Power Engineering, University of Chemistry and Technology Prague, Technická 5, \\ 16628 Prague 6, Czech Republic; haslt@vscht.cz (T.H.); Michal.Jeremias@vscht.cz (M.J.); \\ fartakj@vscht.cz (J.F.); pohorelm@vscht.cz (M.P.) \\ * Correspondence: jiriceki@vscht.cz; Tel.: +420-723-948-454
}

Received: 28 November 2019; Accepted: 15 December 2019; Published: 18 December 2019

\begin{abstract}
Alkanes are widely used as phase change materials (PCMs), especially for thermal energy storage (TES), due to their high thermal capacity, stability, availability, and non-corrosiveness. However, the drawbacks of alkanes are low heat conductivity and high cost. Our aim was to explore alternative organic PCMs for TES and to compare such compounds based on the relationship between their performance and cost. For this purpose, we analysed several commercially available products, including long chain alkanes, alcohols, monocarboxylic acid, amines, ethers and esters in high purities. Differential scanning calorimetry and thermogravimetry (DSC and TGA) were used to measure the melting point, melting enthalpy and thermal stability of these compounds. The materials were classified according to their melting temperature. In order to compare the compounds, we calculated from the measured enthalpies and the price list provided by producers a coefficient that represents factors in both the performance and cost of the material. This method was used to identify the most suitable organic compound for thermal energy storage in each temperature range. As the main result of this work, it has been revealed that various organic compounds can be considered as a vital alternative to the alkanes in temperatures from -10 to $50^{\circ} \mathrm{C}$. On top of that, alcohols and carboxylic acids can cover the temperature range from 50 to $75^{\circ} \mathrm{C}$, which cannot be covered by alkanes.
\end{abstract}

Keywords: organic phase change materials; latent heat storage; price-performance analysis; melting temperature; melting enthalpy

\section{Introduction}

PCMs have received considerable attention in recent years, because, as a tool to store waste or excess thermal energy, they can help to reduce energy consumption as well as to prevent emissions of greenhouse gases into the atmosphere [1-5].

An extensive list of possible organic compounds is being considered for use as PCM in TES systems [6,7]. Organic PCMs have been investigated by many researchers because they possess desired properties such as congruent melting, no supercooling, and a high heat of fusion [5]. Agyenim et al. [8] suggested that an ideal PCM should additionally include the following properties: suitable melting point, high thermal conductivity, good stability, small volume change, good availability, low supercooling and desirable cost. Research has been conducted into the enhancement of the low thermal conductivity [9,10], design of an ideal PCM container [11] and thermal stability of organic PCMs [12]. Cassedy [13] argued that the PCM thermal energy storage systems are not cost effective since their price is almost double when compared to the price of hot water systems. But, in fact, according to the literature review of the authors, there is a lack of publications in the area of the cost estimation of organic thermal energy storage materials. 
Some researchers $[1,2,5,14-16]$ have conducted a brief investigation in this area, but the overview is not complex. In the work of M. Telkes [14], the cost of inorganic materials such as salt hydrates was investigated. However, an investigation of the cost of organic materials for PCM is either missing or is outdated; therefore, the prices are no longer applicable. S. M. Hasnain [15] stated that paraffins are commercially available at a reasonable cost and M. M. Farid et al. [1] suggested that only the technical grade organic material may be used in latent heat storage. A. Sharma et al. [5] compared the cost of technical grade paraffin to the cost of fatty acid, which is $2-2.5$ times higher than that of paraffin. R. $\mathrm{K}$. Sharma [16] suggested polyethylene glycol (PEG) as a suitable organic PCM for the temperature range of $55-60{ }^{\circ} \mathrm{C}$. This work encompasses techno-economic analysis where PEG is compared to other organic compounds such as paraffin, stearic acid, palmitic acid and myristic acid, including their cost. J. P. da Cunha [2] provided a complex overview of the prices of various organic and inorganic PCMs. However, the sources of this information are not specified. Further resources in this field are very scarce.

Because of this lack of information, our aim was to investigate the current costs of various technical grade organic materials and to evaluate their price and performance. Due to the different performance of each compound, the price per ton of material is not a comparable parameter. Therefore, we calculated a price-performance ratio, in which performance is represented by latent heat of fusion so that the compounds can be compared to each other.

In this work, we apply this calculation on straight chain basic alkanes, alcohols, ethers, esters, carboxylic acids and amines with a melting temperature ranging from $-10^{\circ} \mathrm{C}$ to $75{ }^{\circ} \mathrm{C}$. Based on the calculated price-performance parameters, we selected the most suitable material for thermal accumulation in each melting temperature interval.

\section{Materials and Methods}

First, the melting points and heats of fusion of the studied compounds were measured. Choosing a PCM for a certain application requires a specific temperature range. Because of this, all the PCMs were divided into intervals of melting points, ranging from $-10^{\circ} \mathrm{C}$ to $10^{\circ} \mathrm{C}, 10^{\circ} \mathrm{C}$ to $30^{\circ} \mathrm{C}$ etc. For the purpose of comparison, a price-performance coefficient $(\mathrm{K})$ was calculated from the price of material obtained by the producer and the performance represented by the measured heat of fusion. With the help of this coefficient, the compounds within each group were compared and the most cost-effective material was selected.

\subsection{Materials}

Basic straight chain alkanes of even carbon numbers ranging from 12 to 22 and purities in the interval of $95 \%$ to $97 \%$, alcohols of even carbon numbers ranging from 10 to 22 and purities in the interval of $95 \%$ to $99 \%$, and ethers of carbon numbers ranging from 16 to 32 and purities within the interval of $87 \%$ to $99 \%$ were obtained from SASOL. Carboxylic acids of carbon numbers ranging from 10 to 22 and purities of $85 \%$ to $99 \%$ were obtained from KLK Oleo, esters of carbon numbers 14, 16 and 18 and a purity of 95\% from Haihang Industry and amines of carbon numbers 12 and 18 from Hangzhou Dayang. All the measured compounds melt in the interval ranging from $-10^{\circ} \mathrm{C}$ to $75^{\circ} \mathrm{C}$. The compounds with an odd or high carbon number were excluded from the analysis because they are not commercially produced due to low profitability. Only pentadecane was included in this research, as it is the only commercially produced alkane with an odd carbon number.

\subsection{Differential Scanning Calorimetry (DSC)}

The melting point $\left(\mathrm{T}_{\mathrm{mpt}}\right)$ and latent heat of fusion were determined by the DSC. The measurements were carried out on an open aluminum pan in air atmosphere. The sample was cooled down to $-40{ }^{\circ} \mathrm{C}$ in order to solidify the liquid samples. From this initial temperature, the sample (about $20 \mathrm{mg}$ ) was heated linearly $\left(1{ }^{\circ} \mathrm{C} / \mathrm{min}\right)$ up to the temperature $30^{\circ} \mathrm{C}$ above the expected melting point reported in the literature. Thermal analysis was performed on a Setaram DSC 131 analyzer. Its calibration was 
based on analyzing the melting point and latent heat for octadecane $\left(\mathrm{T}_{\mathrm{mpt}} 28.24{ }^{\circ} \mathrm{C}, \Delta \mathrm{H} 238.76 \mathrm{~J} / \mathrm{g}\right)$ and indium $\left(\mathrm{T}_{\mathrm{mpt}} 156.56^{\circ} \mathrm{C}, \Delta \mathrm{H} 28.57 \pm 0.17 \mathrm{~J} / \mathrm{g}\right.$ ) done on a monthly basis. Three calibrations, as well as three experimental runs, were done for each sample. The calibrants were supplied from Setaram and TA Instruments. After each run, the data were evaluated using the analysis software Setsoft 2000 and Calisto. For example, Figure 1 shows the enthalpy-temperature curve obtained by Setaram DSC 131 for octadecanol. The heat of fusion is represented here by the area between melting curve (dark) and integration curve (light). The melting temperature is represented by the onset temperature, prior to the peak minimum temperature, being less dependent on heating rate and sample mass. The uncertainty and reproducibility of $\mathrm{T}_{\mathrm{mpt}}$ is in the order of $1 \mathrm{~K}$. The latent heat uncertainty was calculated as $\pm 5 \%$, all at a $95 \%$ confidence level $(k=2)$.

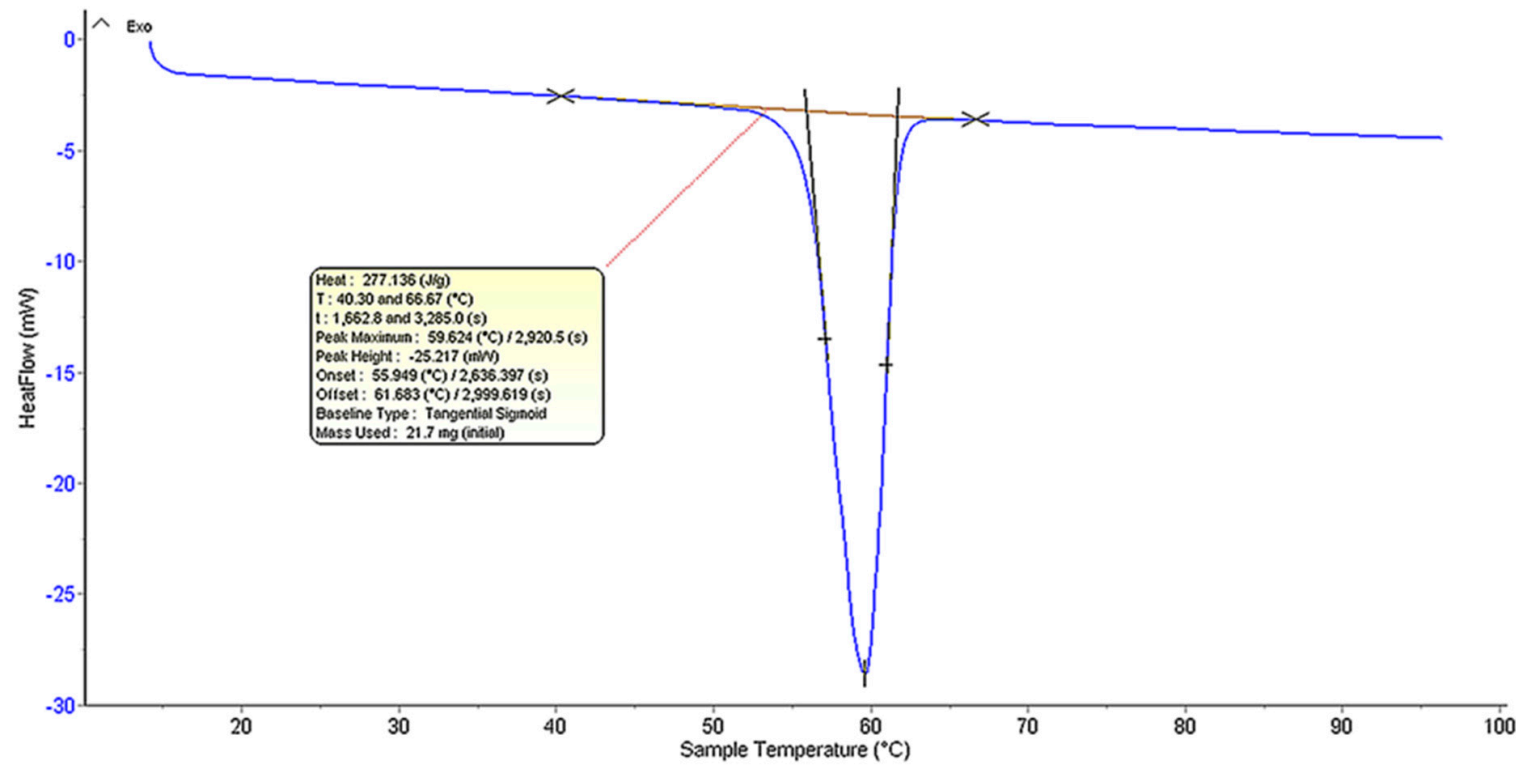

Figure 1. Enthalpy-temperature curve of octadecanol.

\subsection{K Value (Price-Performance Coefficient) Calculation}

The price-performance coefficient, referred to here as the $K$ value, was calculated as the parameter for comparison of various organic PCMs. The price-performance comparison has been used in various areas of research. For example, Esfe et al. [17] compared the price and performance of three nanofluids SWCNT-MgO EG, SWCNT EG and MgO EG for thermal conductivity enhancement. No calculation was done in the referred article, as the comparison was done via chart where no exact numerical was visible. In the work of Alirezaie et al. [18], the so-called price performance factor (PPF) was calculated for two nanofluids of various particle sizes. The coefficient was calculated as the thermal conductivity ratio divided by the price of the nanofluid multiplied by 1000. Such analysis proved that the nanofluids with smaller particles and higher thermal conductivity were not necessarily more economical. The price performance of various PCMs is a part of the work of J. P. da Cunha [2]. He presented the price of various organic and inorganic compounds in EUR per kWh. In this paper, the price was obtained from the producers of the materials based on a metric ton. The performance was represented by the latent heat of fusion, which demonstrated how many joules per gram can theoretically be accumulated. The $K$ value (Equation (1)) was calculated as the ratio of the price of material in euros per metric ton (mt) and the latent heat of fusion in megajoules per ton. Thus, theoretically, the $K$ value represents the price of one megajoule of accumulated energy. Consequently, the lower the $K$ value is, the more cost effective the material is.

$$
K=(\text { Price }[€ / \text { ton }]) /(\mathrm{H}[\mathrm{MJ} / \text { ton }])
$$




\section{Results and Discussion}

Table 1 shows all the obtained results, including melting temperatures, latent heats and calculated $K$ values.

Table 1. Melting points, melting enthalpies and $K$ values of the analysed organic PCMs.

\begin{tabular}{|c|c|c|c|c|c|}
\hline Material and Purity [\%] & Producer & $\mathrm{T}_{\mathrm{mpt}}$ & Price & $\mathbf{H}$ & $K$ \\
\hline & & $\left({ }^{\circ} \mathrm{C}\right)$ & $(€ / m t)$ & $(\mathrm{MJ} / \mathrm{mt})$ & $(€ / \mathrm{MJ})$ \\
\hline Dioctyl Ether 99.1\% & Sasol & -6.1 & 4550 & 173.5 & 26.2 \\
\hline Didecyl Ether 98.2\% & Sasol & 16.0 & 4550 & 205.5 & 22.1 \\
\hline Didodecyl Ether 98.5\% & Sasol & 32.5 & 4400 & 231.4 & 19.0 \\
\hline Ditetradecyl Ether $94.3 \%$ & Sasol & 42.2 & 4400 & 230.6 & 19.1 \\
\hline Dihexadecyl Ether $90.6 \%$ & Sasol & 49.8 & 4400 & 206.9 & 21.3 \\
\hline Dioctadecyl Ether 87.2\% & Sasol & 57.0 & 4400 & 197.2 & 22.3 \\
\hline Decanol $99.4 \%$ & Sasol & 3.4 & 2700 & 216.0 & 12.5 \\
\hline Dodecanol 99.8\% & Sasol & 21.8 & 2990 & 215.5 & 13.9 \\
\hline Tetradecanol $98.9 \%$ & Sasol & 36.0 & 2990 & 215.9 & 13.8 \\
\hline Hexadecanol 98.1\% & Sasol & 46.8 & 2190 & 246.5 & 8.9 \\
\hline Octadecanol 99.4\% & Sasol & 55.9 & 2240 & 277.1 & 8.1 \\
\hline Eicosanol 98\% & Sasol & 62.5 & 6300 & 240.8 & 26.2 \\
\hline Docosanol 99.1\% & Sasol & 68.8 & 6100 & 291.3 & 20.9 \\
\hline Dodecane $99.6 \%$ & Sasol & -9.8 & 5050 & 258.5 & 19.5 \\
\hline Tetradecane $99.2 \%$ & Sasol & 5.0 & 4550 & 265.4 & 17.1 \\
\hline Pentadecane $95.7 \%$ & Sasol & 8.3 & 7650 & 140.8 & 54.3 \\
\hline Hexadecane $99.4 \%$ & Sasol & 17.2 & 4550 & 237.8 & 19.1 \\
\hline Octadecane $97.6 \%$ & Sasol & 25.7 & 4550 & 237.0 & 19.2 \\
\hline Eicosane $95.1 \%$ & Sasol & 33.3 & 5580 & 239.9 & 23.3 \\
\hline Docosane $98.4 \%$ & Sasol & 42.8 & 5580 & 258.3 & 21.6 \\
\hline Octanoic acid 99\% & KLK Oleo & 31.1 & 2450 & 168.2 & 14.6 \\
\hline Dodecanoic acid 99\% & KLK Oleo & 43.5 & 1560 & 207.8 & 7.5 \\
\hline Tetradecanoic acid 99\% & KLK Oleo & 53.3 & 1350 & 226.8 & 6.0 \\
\hline Hexadecanoic acid $98.2 \%$ & KLK Oleo & 61.0 & 1270 & 242.9 & 5.2 \\
\hline Octadecanoic acid $98.3 \%$ & KLK Oleo & 67.3 & 1740 & 251.6 & 6.9 \\
\hline Docosanoic acid 86.4\% & KLK Oleo & 74.2 & 3110 & 224.1 & 13.9 \\
\hline Dodecylamine $97.8 \%$ & Hangzhou Dayang & 23.6 & 2800 & 238.9 & 11.7 \\
\hline Octadecylamine $90.2 \%$ & Hangzhou Dayang & 48.4 & 3770 & 292.3 & 12.9 \\
\hline Tetradecyltetradecanoate $95 \%$ & Haihang Industry & 39.7 & 5960 & 230.3 & 25.9 \\
\hline Hexadecylhexadecanoate $95 \%$ & Haihang Industry & 51.0 & 3350 & 235.6 & 14.2 \\
\hline Octadecyloctadecanoate $95 \%$ & Haihang Industry & 59.2 & 3600 & 217.6 & 16.5 \\
\hline
\end{tabular}

First, the compounds with melting points from the interval of -10 to $10^{\circ} \mathrm{C}$, dodecane, dioctyl ether, decanol, tetradecane and pentadecane, were compared, see Figure 2. Tetradecane possesses a higher heat of fusion than dodecane (tetradecane $265.4 \mathrm{~J} / \mathrm{g}$, dodecane $258.5 \mathrm{~J} / \mathrm{g}$ ) and is cheaper. Therefore, the $K$ value of tetradecane is lower than that of dodecane and the application of tetradecane or decanol in this temperature interval would be the optimal choice.

In the temperature range from 10 to $30^{\circ} \mathrm{C}$, dodecyl ether, hexadecane, dodecanol, dodecylamine and octadecane were compared, see Figure 3. Although the latent heat value of dodecylamine is higher than hexadecane (dodecylamine $238.9 \mathrm{~J} / \mathrm{g}$, hexadecane $237.8 \mathrm{~J} / \mathrm{g}$ ), the $K$ value of dodecylamine is lower, due to its low price. Dodecyl ether $(197.2 \mathrm{~J} / \mathrm{g})$ is not a perspective material in this temperature interval, especially because its price is almost double in comparison to the other compounds from this temperature range. 


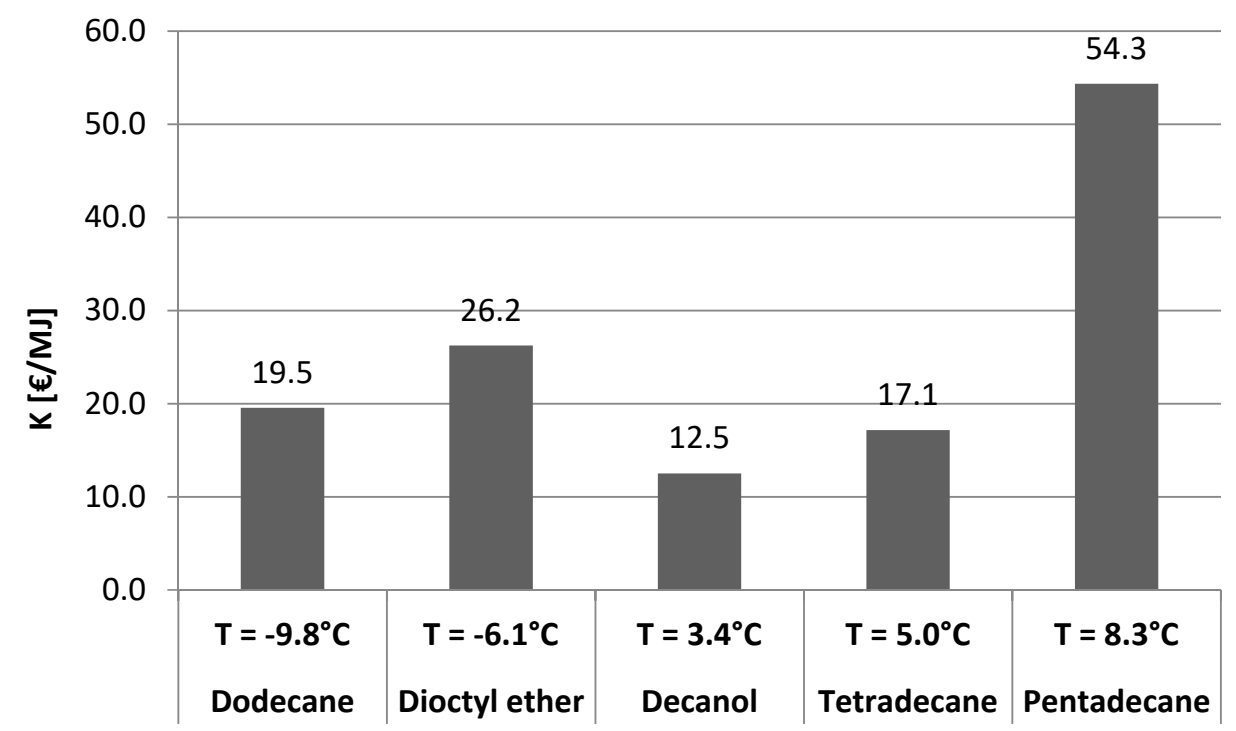

Figure 2. Comparison of organic compounds for an application in the temperature range -10 to $10{ }^{\circ} \mathrm{C}$.

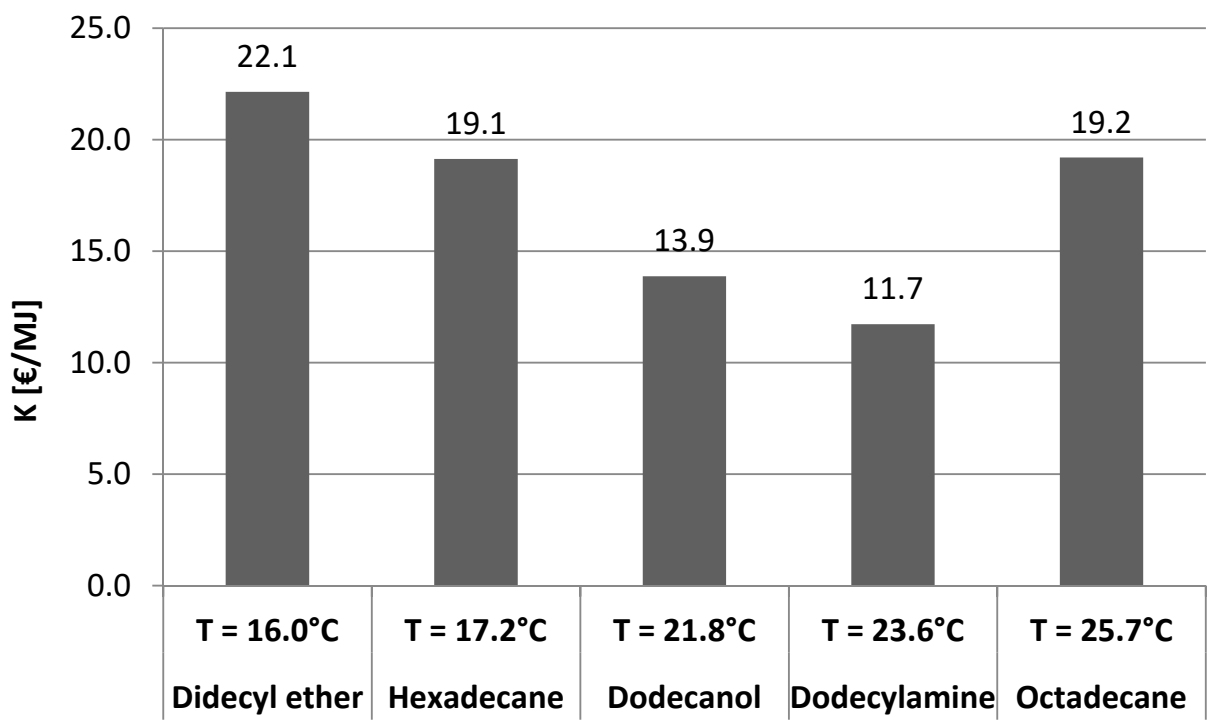

Figure 3. Comparison of organic compounds for application in the temperature range $10-30{ }^{\circ} \mathrm{C}$.

In Figure 4 compounds such as octanoic acid, didodecyl ether, eicosane, tetradecanol and tetradecyl tetradecanoate possess melting points in the range from $30^{\circ} \mathrm{C}$ to $40{ }^{\circ} \mathrm{C}$. In this range, tetradecanol and octanoic acid are the most cost-effective materials. The heat of fusion of eicosane ( $239.9 \mathrm{~J} / \mathrm{g}$ ) didodecyl ether $(231.4 \mathrm{~J} / \mathrm{g})$ and tetradecyl tetradecanoate $(230.3 \mathrm{~J} / \mathrm{g})$ are the highest in this range but these materials are very expensive.

In the range from $40{ }^{\circ} \mathrm{C}$ to $50{ }^{\circ} \mathrm{C}$, dodecanoic acid, docosane, and ditetradecyl ether, hexadecanol, octadecylamine and dihexadecylether are possible candidates for application, see Figure 5 . The most prospective materials in this interval are obviously dodecanoic acid and octadecylamine because of their very low price and relatively high melting enthalpy. 


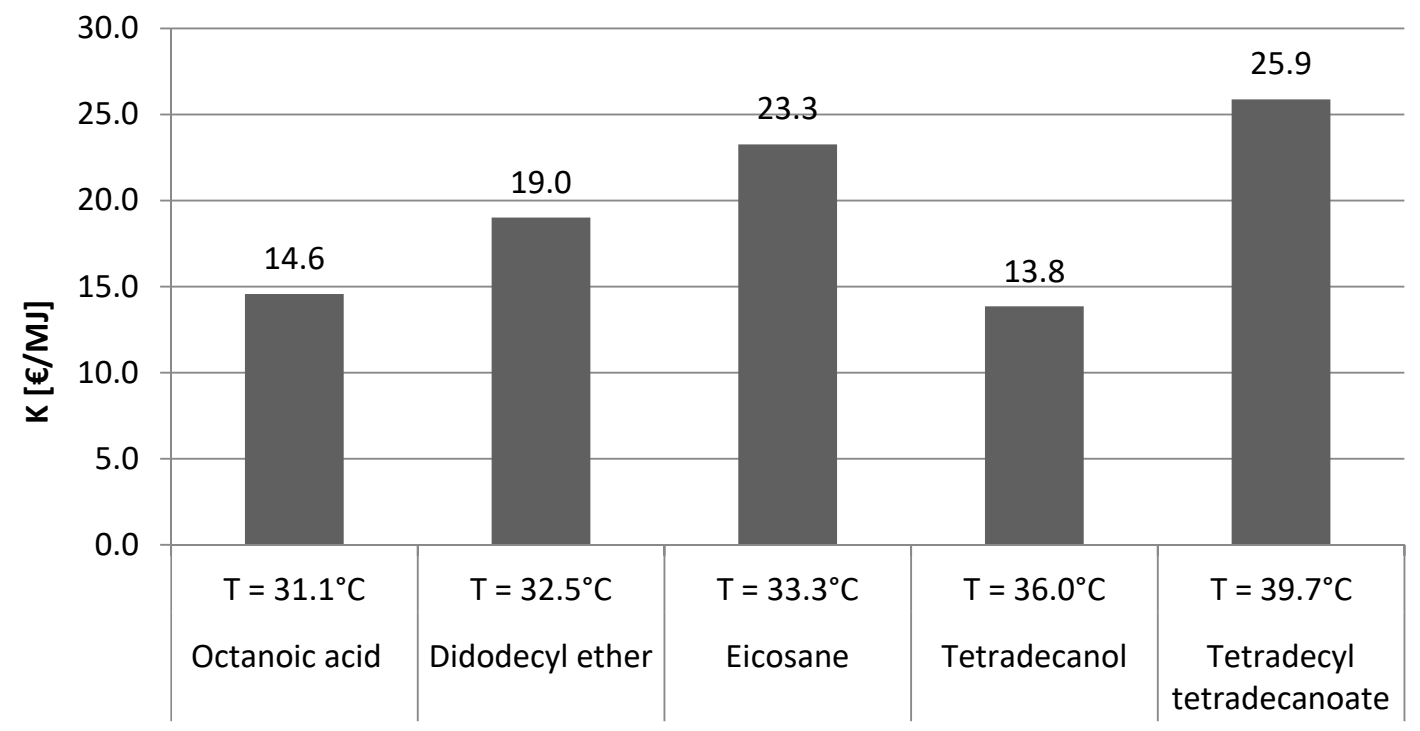

Figure 4. Comparison of organic compounds for application in the temperature range $30-40{ }^{\circ} \mathrm{C}$.

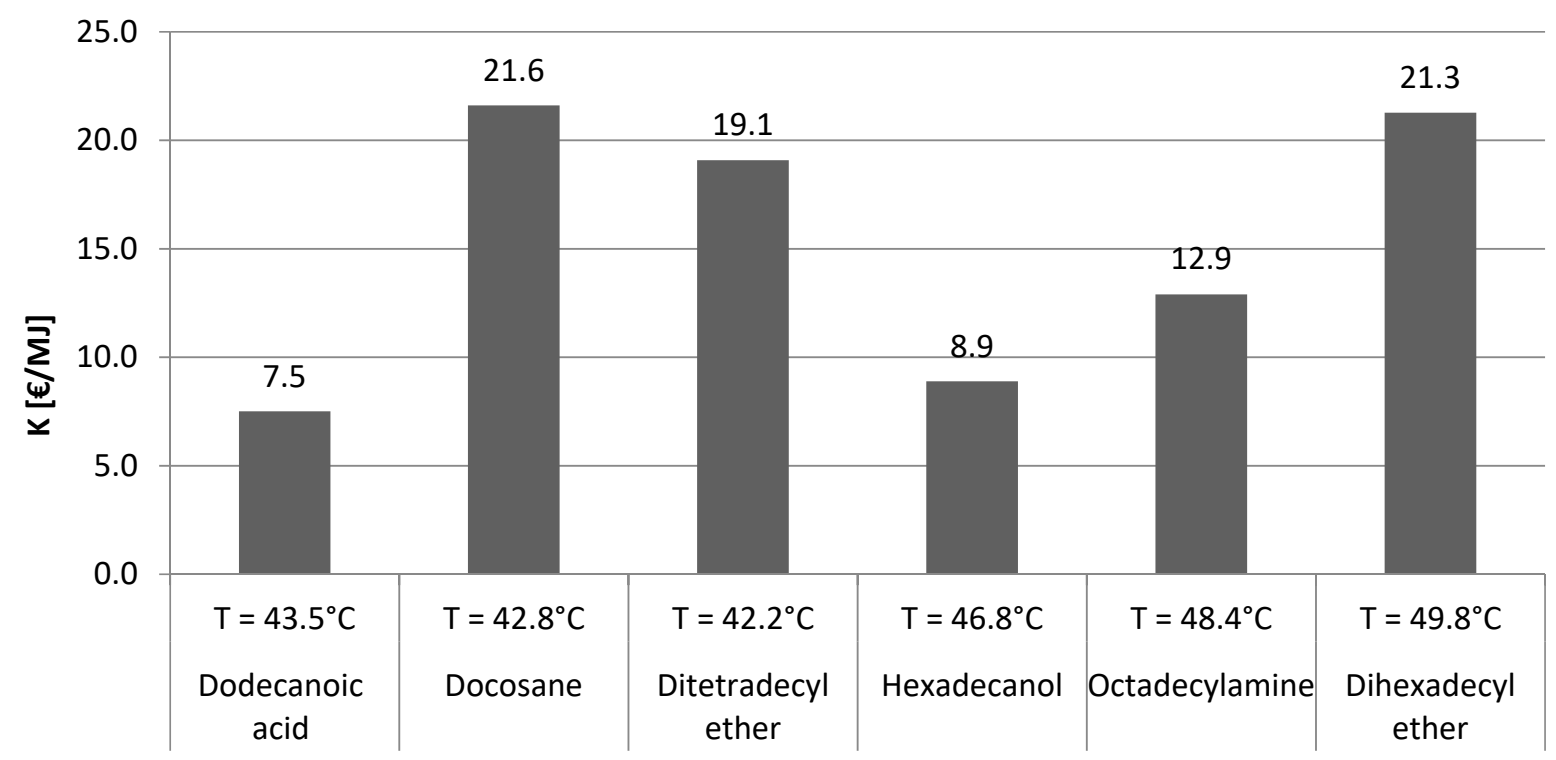

Figure 5. Comparison of organic compounds for application in the temperature range $40-50{ }^{\circ} \mathrm{C}$.

In the temperature range from $50{ }^{\circ} \mathrm{C}$ to $60{ }^{\circ} \mathrm{C}$ we have measured five candidates: hexadecyl hexadecanoate, tetradecanoic acid, octadecanol, dioctadecyl ether and octadecyl octadecanoate, see Figure 6. Tetradecanoic acid and octadecanol are preferable due to their low price.

In Figure 7 another big group of compounds was measured in the range from $60{ }^{\circ} \mathrm{C}$ to $75^{\circ} \mathrm{C}$. Hexadecanoic acid, eicosanol, octadecanoic acid, docosanol and docosanoic acid were compared. The most preferable materials in this case are hexadecanoic acid and octadecanoic acid. Both of these acids are more suitable than eicosanol, due to their low price. 


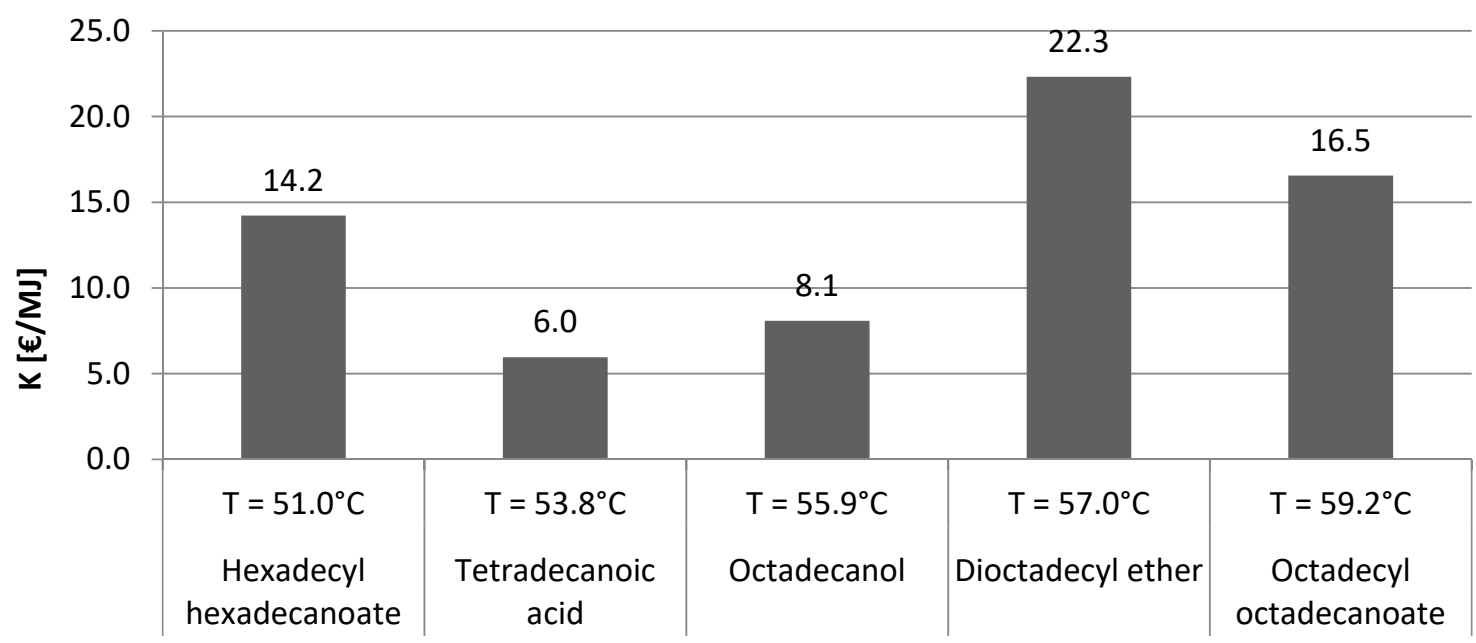

Figure 6. Comparison of organic compounds for application in the temperature range $50-60{ }^{\circ} \mathrm{C}$.

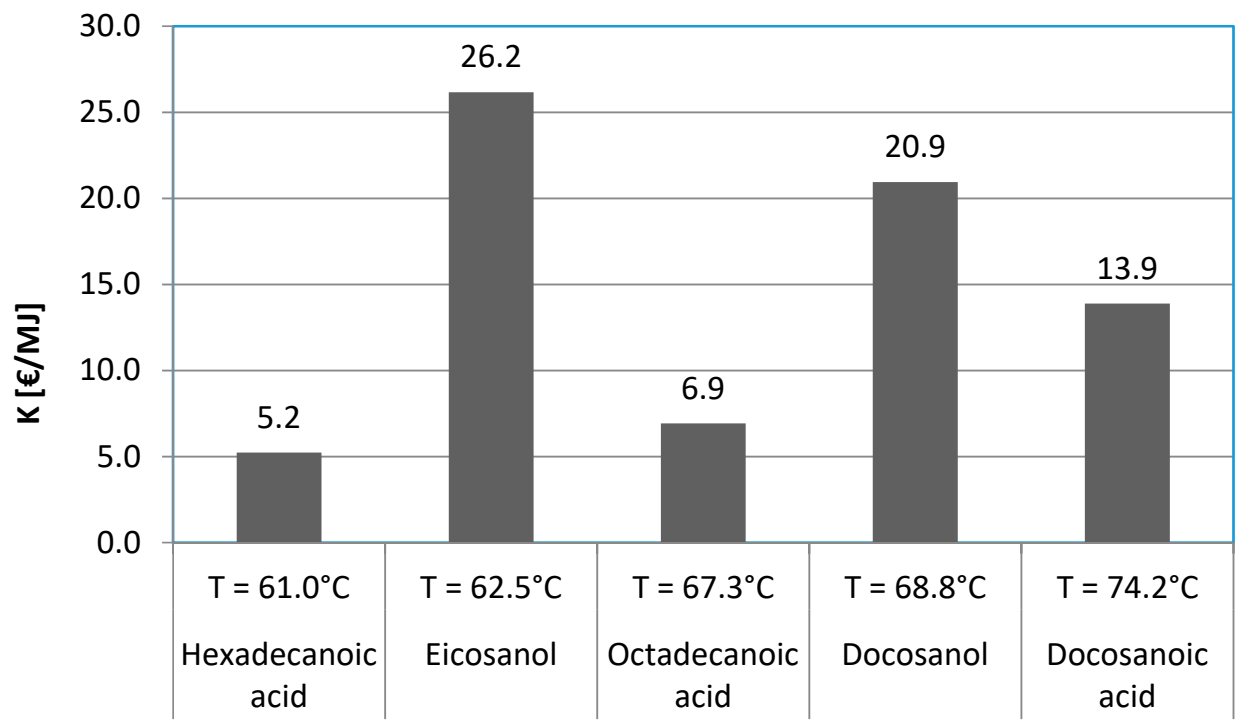

Figure 7. Comparison of organic compounds for application in the temperature range $60-75^{\circ} \mathrm{C}$.

\section{Conclusions}

To the best of our knowledge, we are the first to present the analysis of the cost of tech-grade organic PCMs for TES. In this work, we have successfully applied our innovative approach to compare organic compounds and select the most suitable material for TES based on price and performance. In terms of these two parameters, we have shown that alcohols, ethers, carboxylic acids, amines and esters can be good alternatives to alkanes, which are currently considered the organic PCM of choice. The alcohols and carboxylic acids seem to be most promising because of their very low price and due to their ability to cover some of the temperature ranges that alkanes cannot.

Thus, the alcohols and carboxylic acids are a viable alternative thermal energy storage material that could significantly reduce the total cost of the entire TES system and improve the energy storage efficacy.

However, in this first stage of study, the performance of these materials was characterized only by the latent heat of fusion, but of course, thermal conductivity must be taken into account. Therefore, we are already analysing other important parameters of the material, such as thermal conductivity, stability and corrosivity of the PCM on the container.

Author Contributions: Conceptualization, I.J. and T.H.; methodology, I.J. and J.F.; formal analysis, T.H. and J.F.; writing-original draft preparation, T.H. and I.J.; writing—review and editing, M.J. and M.P.; supervision, M.P. All authors have read and agreed to the published version of the manuscript. 
Funding: Financial support from specific university research MSMT No 21-SVV/2019.

Acknowledgments: Thanks to the listed companies for the samples: SASOL, KLK Oleo, Hangzhou Dayang, Haihang Industry.

Conflicts of Interest: The authors declare no conflict of interest.

\section{References}

1. Farid, M.M.; Khudhair, A.M.; Razack, S.A.K.; Al-Hallaj, S. A review on phase change energy storage: Materials and applications. Energy Convers. Manag. 2004, 45, 1597-1615. [CrossRef]

2. Da Cunha, J.P.; Philip, E. Thermal energy storage for low and medium temperature applications using phase change materials-A review. Appl. Energy 2016, 177, 227-238. [CrossRef]

3. Pielichowska, K.; Pielichowski, K. Phase change materials for thermal energy storage. Prog. Mater. Sci. 2014, 65, 67-123. [CrossRef]

4. Nkwetta, D.N.; Haghighat, F. Thermal energy storage with phase change material-A state-of-the art review Sustain. Cities Soc. 2014, 10, 87-100. [CrossRef]

5. Sharma, A.; Tyagi, V.V.; Chen, C.R.; Buddhi, D. Review on thermal energy storage with phase change materials and applications. Renew. Sustain. Energy Rev. 2009, 13, 318-345. [CrossRef]

6. Haillot, D.; Bauer, T.; Kröner, U.; Tamme, R. Thermal analysis of phase change materials in the temperature range $120-150{ }^{\circ} \mathrm{C}$. Thermochim. Acta 2011, 513, 49-59. [CrossRef]

7. Sarier, N.; Onder, E. Organic phase change materials and their textile applications: An overview. Thermochim. Acta 2012, 540, 7-60. [CrossRef]

8. Agyenim, F.; Hewitt, N.; Eames, P.; Smyth, M. A review of materials, heat transfer and phase change problem formulation for latent heat thermal energy storage systems (LHTESS). Renew. Sustain. Energy Rev. 2010, 14, 615-628. [CrossRef]

9. Soares, N.; Costa, J.J.; Gaspar, A.R.; Santos, P. Review of passive PCM latent heat thermal energy storage systems towards buildings' energy efficiency. Energy Build. 2013, 59, 82-103. [CrossRef]

10. Kenisarin, M.M. High-temperature phase change materials for thermal energy storage. Renew. Sustain. Energy Rev. 2010, 14, 955-970. [CrossRef]

11. Ugurlu, A.; Gokcol, C. A review on thermal energy storage systems with phase change materials in vehicles. Electron. J. Vocat. Coll. 2012, 2, 1-14.

12. Rathod, M.K.; Banerjee, J. Thermal stability of phase change materials used in latent heat energy storage systems: A review. Renew. Sustain. Energy Rev. 2013, 18, 246-258. [CrossRef]

13. Cassedy, E.S. Prospects for Sustainable Energy: A Critical Assessment, Solar Energy Sources; Cambridge University Press: Cambridge, UK, 2001; pp. 24-25.

14. Telkes, M. Solar Energy Storage, Critical Materials Problems in Energy Production ed C Stein; Elsevier: Socorro, NM, USA, 1976; Chapter 14; pp. 440-465.

15. Hasnain, S.M. Review on sustainable thermal energy storage technologies, Part I: Heat storage materials and techniques. Energy Convers. Manag. 1998, 39, 1127-1138. [CrossRef]

16. Sharma, R.K.; Ganesan, P.; Tyagi, V.V.; Mahlia, T.M.I. Accelerated thermal cycle and chemical stability testing of polyethylene glycol (PEG) 6000 for solar thermal energy storage. Sol. Energy Mater. Sol. Cells 2016, 147, 235-239. [CrossRef]

17. Ostry, M.; Charvat, P. Materials for advanced heat storage in buildings. Procedia Eng. 2013, 57, 837-843. [CrossRef]

18. Alirezaie, A.; Hajmohammad, M.H.; Hassani Ahangar, M.R.; Hemmat Esfe, M. Price-performance evaluation of thermal conductivity enhancement of nanofluids with different particle sizes. Appl. Therm. Eng. 2018, 128, 373-380. [CrossRef] 